\title{
Creeping Bentgrass Responses to Drought Stress and Polyamine Application
}

\author{
Vijaya Shukla, Yingmei Ma, and Emily Merewitz ${ }^{1}$ \\ Department of Plant, Soil and Microbial Sciences, Michigan State University, 1066 Bogue Street, East \\ Lansing, MI 48824
}

\begin{abstract}
AdDitional INDEX words. Agrostis stolonifera, water stress, turfgrass, tillering, spermidine, spermine, photochemical efficiency, quantum yield, lipid peroxidation

Abstract. Polyamines (PAs) such as spermidine (Spd), spermine (Spm), and putrescine are involved in various biological functions including abiotic stress response. Whether PAs play an important role in cool-season turfgrass tolerance of drought stress is not well investigated. We have conducted a series of growth chamber (GC) studies including one hydroponic and two soil-based GC studies with creeping bentgrass (Agrostis stolonifera) 'Penncross' and 'Penn-G2' to determine whether exogenous application of PAs may affect plant growth and stress tolerance. Application of relatively low concentrations of Spd $(500$ or $750 \mu \mathrm{M})$ or $\mathrm{Spm}(500 \mu \mathrm{M})$ promoted tillering rates under optimal growth conditions in hydroponics. The same levels of PA treatments moderated the damages associated with drought stress in the soil-based GC studies. The most notable differences in drought response associated with PA treatment were increased membrane health. This was observed as greater photochemical efficiency, higher quantum yield, less electrolyte leakage, and less lipid peroxidation (malondialdehyde content) in PA-treated plants compared with control plants. The relatively low level of exogenous PAs used in this study did not have a major effect on plant water relations under drought stress. Canopy temperatures and soil moisture content were unaffected by any PA treatment; however, on some days during early drought stress, relative water content was significantly higher in PAtreated plants compared with controls. PA could play a major role in protecting photosynthetic and cellular membranes during drought stress of creeping bentgrass.
\end{abstract}

Plant cells contain long-chain amine compounds called polyamines, of which the most common are spermidine, spermine, and putrescine. These compounds are considered phytohormone-like because they play various regulatory roles in plant cells. They are involved in controlling cell development, in stress responses, and numerous other functions (Gill and Tuteja, 2010). Natural increases or decreases in PA content occur in plant cells in response to stress. For example, a halophyte grass called vetiver grass (Chrysopogon zizanioides) was shown to accumulate levels of Spd and Spm under drought stress, whereas putrescine levels decreased (Zhou and Bingjun, 2009). Whether PAs accumulate as a result of stress damage or to protect plant cells from stress is still not well understood in most species (Capell et al., 2004). Because salt-tolerant vetiver grass uses PA pathways for stress tolerance, it may be desirable to understand whether PAs have a similar protective role in high-value, cool-season turfgrass species such as creeping bentgrass. Additionally, PA fluxes are differential among species during stress incidence. Arabidopsis (Arabidopsis thaliana) plants compared with resurrection (Craterostigma plantagineum) plants tended to shift in opposite directions along the arginine decarboxylase pathway of PA biosynthesis during stress (Alcazar et al., 2011). These species differences in PA pathway fluxes during a stress incident could be related to differences in each species' primary mechanism used to cope with drought stress, whether there is a tendency toward escape, avoidance, or tolerance mechanisms. Thus, investigation of responses to PA in multiple species is necessary and could indicate preferential drought survival mechanisms among species.

A primary factor related to a plant's drought-coping mechanism is related to tendency for ethylene production and leaf

Received for publication 10 Oct. 2014. Accepted for publication 19 Nov. 2014 ${ }^{1}$ Corresponding author. E-mail: merewitz@msu.edu. senescence (Chaves et al., 2003). PAs and ethylene are closely linked in plant metabolic pathways, because they all use S-adenosyl methionine (SAM) as precursors for biosynthesis. PAs and ethylene act antagonistically because they are competing for SAM substrates. Research has shown that PAs do promote opposite cellular processes than ethylene by promoting growth and delaying senescence (Bitrián et al., 2012; Torrigiani et al., 2012). In creeping bentgrass, delaying leaf senescence with a transgene for cytokinin biosynthesis was found to improve drought stress tolerance (Merewitz et al., 2010, 2011). Here, we are investigating whether PAs may have similar protective effects on improving abiotic stress tolerance in creeping bentgrass.

Genetically modified enhancement of the biosynthesis of some forms of PAs has been shown to be effective in promoting plant tolerance to abiotic stresses. For instance, increases in Spd and Spm levels were shown to confer tolerance to drought in transgenic rice [Oryza sativa (Capell et al., 2004)], hightemperature stress in tomato [Solanum lycopersicum (Cheng et al., 2009)] as well as salt stress in corn [Zea mays (JiménezBremont et al., 2007)]. Overexpression of a Spd synthase gene in arabidopsis plants improved plant tolerance to many abiotic stresses including drought stress (Kasukabe et al., 2004); however, endogenous content of PAs is sensitive to plant environmental stimuli and turfgrass species are culturally managed significantly differently than in other crop species [most notably mowing (Beard, 2006)]. Thus, an investigation of PAs specifically in cool-season turfgrass species is needed to determine whether these compounds may be important to the turfgrass industry.

Exogenous application of PAs has been shown to be an effective strategy to increase plant tolerance of various stresses and regulate plant growth. For instance, salt stress damage in 
rice and water loss in mandarin orange (Citrus reticulata) were mitigated by exogenous application of PAs (Shi and Chan, 2014). There also could be potential changes in growth regulation because PAs are involved in cell division, differentiation, and DNA replication processes for plant cell growth (Kusano et al., 2008). Recently, there is evidence that there are rhizobacteria that may exude PAs to alter plant growth responses (Xie et al., 2014). It is not known whether PAs play a role in regulating turfgrass species growth of shoots or roots. Understanding this could have major implications for plant growth regulator (PGR) products in the turfgrass industry. Additionally, whether PAs have any PGR effect on turfgrass species is an essential step before evaluating responses of a turfgrass to PA and stress, because differential tillering could be mistaken for increased drought tolerance. PA application and abiotic stress responses were recently evaluated in a warmseason grass, bermudagrass (Cynodon dactylon), which exhibited improvements in drought and salt tolerance in response to relatively high levels of PA application (Shi et al., 2013). Growth responses and photochemical attributes were not evaluated in their study and they used a relatively high rate of PA application ( $5 \mathrm{~mm}$ ). Specific investigation of whether coolseason turfgrass species such as creeping bentgrass will be affected by exogenous PA application is desirable. Cool-season grasses differ significantly from warm-season grasses in growth habit, biochemical processes, and tolerance to abiotic stress. Additionally, whether a relatively low concentration of PA is effective in mitigating stress damages is not known and would be most feasible in practical applications.

Drought stress is one of the most commonly encountered abiotic stresses in the turfgrass industry. Drought stress readily occurs even on irrigated areas in times of limited rainfall, as a result of water use restrictions, on areas with poor irrigation instrumentation, and as a result of the high demand for firm, dry conditions for adequate playability of turf areas such as golf courses. The objectives of this series of growth chamber studies were to investigate whether foliar applications of Spm $(500 \mu \mathrm{M})$ and Spd $(500$ or $750 \mu \mathrm{M})$ have an effect on creeping bentgrass growth under optimal conditions and under drought stress. Our objectives were to determine whether PAs alter growth characteristics such as leaf and root biomass, tillering rate, and stress protective properties such as improving cellular water status and reducing drought damage to cellular membranes.

\section{Material and Methods}

Plant material and measurements-hydroponic EXPERIMENT. Plugs of 'Penncross' creeping bentgrass were taken from the Hancock Turfgrass Research Center in East Lansing, MI, and were separated into single tillers to obtain clonal material for a hydroponic experiment. The single tillers were established in a hydroponic system in early Aug. 2013 and were allowed to grow without any experimental treatments until adequate root and shoot development occurred. The PA treatment began on 29 Aug. 2013 and the experiment ended on 3 Oct. 2013. The hydroponics study was performed to enable a determination of growth regulator effects of PAs on shoot and root attributes of creeping bentgrass plants without having to majorly disturb or damage plants such as would occur in a soilbased system. The hydroponic growth media was contained within opaque containers $(38 \times 28 \times 16 \mathrm{~cm})$ within a large walk-in controlled-environment growth chamber. The growth chamber conditions are the same as described subsequently for the soil-based GC studies. The hydroponic growth media was made through dilution of stock solutions $(1000 \times)$ of the following nutrient solutions: $71.361 \mathrm{~g} \cdot \mathrm{L}^{-1}\left(\mathrm{NH}_{4}\right)_{2} \mathrm{SO}_{4}, 27.3 \mathrm{~g} \cdot \mathrm{L}^{-1} \mathrm{KNO}_{3}$, $127.521 \mathrm{~g} \cdot \mathrm{L}^{-1} \mathrm{Ca}\left(\mathrm{NO}_{3}\right)_{2} \cdot 4 \mathrm{H}_{2} \mathrm{O}, 68.045 \mathrm{~g} \cdot \mathrm{L}^{-1} \mathrm{KH}_{2} \mathrm{PO}_{4}$, $43.568 \mathrm{~g} \cdot \mathrm{L}^{-1} \mathrm{~K}_{2} \mathrm{SO}_{4}, 199.65 \mathrm{~g} \cdot \mathrm{L}^{-1} \mathrm{MgSO}_{4} \cdot 7 \mathrm{H}_{2} \mathrm{O}, 14.684 \mathrm{~g} \cdot \mathrm{L}^{-1}$ $\mathrm{Fe}\left(\right.$ EDTA)Na, $1.43 \mathrm{~g} \cdot \mathrm{L}^{-1} \mathrm{H}_{3} \mathrm{BO}_{3}, 0.91 \mathrm{~g} \cdot \mathrm{L}^{-1} \mathrm{MnCl}_{2} \cdot 4 \mathrm{H}_{2} \mathrm{O}$, $0.11 \mathrm{~g} \cdot \mathrm{L}^{-1} \mathrm{ZnSO}_{4} \cdot \mathrm{H}_{2} \mathrm{O}, 0.04 \mathrm{~g} \cdot \mathrm{L}^{-1} \mathrm{CuSO}_{4}, 0.01 \mathrm{~g} \cdot \mathrm{L}^{-1}\left(\mathrm{NH}_{4}\right) \mathrm{Mo}_{7}$ $\mathrm{O}_{24} \cdot 4 \mathrm{H}_{2} \mathrm{O}$. Single tillers of plants were suspended within holes $(1 \mathrm{~cm})$ on an expandable sponge in a polystyrene foam board. The board was cut to fit the containers exactly to prevent light from reaching the root system. The hydroponic solution was aerated with a tube inserted into the solution through the foam board connected to a pump $\left(115 \mathrm{~V}, 60 \mathrm{~Hz}\right.$; Tetra ${ }^{\circledR}$, Blacksburg, VA). Solution $\mathrm{pH}$ was monitored and adjusted as needed every other day (to maintain a $\mathrm{pH}$ of $\approx 6$ ) and the solution was changed on a weekly basis. Plants were not clipped to allow for leaf and root measurements as to not alter natural tillering rate as a result of clipping.

Polyamine treatments for the hydroponic growth chamber study included inclusion of the following concentrations of PAs in the hydroponic growth solution: 1) no PAs control; 2) $100 \mu \mathrm{M} \mathrm{Spd}$; or 3) $500 \mu \mathrm{M}$ Spd. Each plant was individually treated with the respective PA solution or control (no PA) by dipping the full root system of each plant into the solution for 5 min, patting dry on a paper towel, and then rinsing with water for $2 \mathrm{~min}$. As a result of space limitations and the laborious nature of this analysis, we did not treat with all PAs discussed in this article. Spd was chosen because it is one of the most central PAs within the PA biosynthesis pathways and was found in previous studies to have an effect on plant growth (Ahmed et al., 2012). Leaf growth rate measurements were performed manually by counting leaf number and tiller number. Root growth measurements were taken on intact plants by placing the root system in a clear tray of water placed on a scanner. Roots were separated and scanned using a flatbed scanner. Root quantification was performed using Digimizer software (Version 4.3; MedCalc Software, Ostend, Belgium) on scanned images of intact plants to determine root number and root length. Root:shoot ratio and total biomass were recorded and calculated by weighing plants on a balance at the end of the study. Chlorophyll content was determined with a handheld chlorophyll meter (SPAD 502 Plus; Spectrum Technologies, Aurora, IL).

Plant material and gROWTH CONDitions-SOIL-Based EXPERIMENTS. Mature sod pieces of creeping bentgrass 'Penncross' and 'Penn-G2' were collected from the Hancock Turfgrass Research Center in East Lansing, MI, and evaluated in two independent growth chamber experiments. The two growth chamber studies (GC1, GC2) were performed in soil in pots. GC1 was conducted on 'Penncross' and GC2 was conducted on 'Penn-G2'. GC1 study started on 25 Oct. 2013 and ended on 6 Nov. 2013. GC2 studies on 'Penn-G2' were initiated on 7 Feb. 2014 and ended on 19 Feb. 2014. These cultivars were selected based on availability and because 'Penn-G2' is touted to be a more drought-tolerant cultivar compared with 'Penncross'. For both of the soil-based chamber studies, the plant material and growth chamber conditions were equivalently handled and maintained. Sod pieces were potted in polyvinyl chloride tubes (40 cm height $\times 10.16 \mathrm{~cm}$ diameter) in a 1:1 fine sand:soil mix. The soil was a sandy loam (Typic Hapludult) with a pH of 7.7 based on soil particle size/sand classification test results. Plants 
were allowed to become established and were maintained in a greenhouse for $\approx 1$ month. The plants were then transferred to environmentally controlled growth chambers where treatments were initiated after a 2 -week acclimation period. The chamber conditions were set to maintain a $450 \mu \mathrm{mol} \cdot \mathrm{m}^{-2} \cdot \mathrm{s}^{-1}$ light level with $24 / 18{ }^{\circ} \mathrm{C}$ (day/night) temperature and a $60 \%$ relative humidity. Plants were fertilized twice per week with halfstrength Hoagland solution (Hoagland and Arnon, 1950). Plants were trimmed weekly to attain a dense, even-sized canopy. The canopy was trimmed twice per week to maintain a height of $8 \mathrm{~cm}$.

Drought and Polyamine treatments-GC1, CG2. Water treatments included either a well-watered control or drought stress imposed by complete withholding of water in both growth chamber studies. Each polyamine treatment under either drought stress or watered conditions included four biological replicates. Foliar treatments of PAs in GC1 and GC2 included: 1) water control; 2) $500 \mu \mathrm{M}$ Spd (Spd500); 3) $750 \mu \mathrm{M}$ Spd (Spd750); and 4) $500 \mu \mathrm{M} \mathrm{Spm} \mathrm{(Spm500).} \mathrm{These}$ concentrations were selected based on reports in other crop species such as Ahmed et al. (2012). Exogenous application of freshly made PA or control solutions was applied with an atomizer sprayer until runoff from the leaves occurred (40 mL/plant) and all solutions contained 0.125\% Tween-20 (Sigma-Aldrich, St. Louis, MO). PA solutions had a $\mathrm{pH}$ of $\approx 8$. All PA solutions were made just before application to the plants and for the soilbased GC studies, they were sprayed once just before subjecting the plants to drought stress $(0 \mathrm{~d})$. Plants of each cultivar and PA treatment were subjected to drought stress $1 \mathrm{~d}$ after PA treatment. Watering treatments included 1) well-watered control plants; and 2) drought-stressed plants (water completely withheld). The drought period lasted for a total of $12 \mathrm{~d}$ for GC1 and GC2. The experiments were allowed to go on until severe damage to plants was observed and the experiments were ended for destructive harvesting. Therefore, a total of 32 plants was used for each GC1 and GC2.

SOIL MOISTURE AND PHYSIOLOGICAL MEASUREMENTS-GC1, GC2. The volumetric water content of the soil (SWC) for GC1 and GC2 was measured by a time domain reflectometry method (TDR) using a 19-cm probe connected to a data logger (TDR 100; Spectrum Technologies). The TDR probe was inserted into the upper portion of the soil during monitoring.

To determine relative water content of the leaves (RWC), five to 10 fully expanded mature leaves were collected from each plant and weighed to record fresh weight (FW). To determine turgid weight (TW) of the same samples, leaves were wrapped in tissue paper and soaked in deionized water at $4{ }^{\circ} \mathrm{C}$ for $\approx 24 \mathrm{~h}$ to attain full hydration. Then samples were blotted dry with paper towels and weighed immediately to determine TW. Leaf samples were stored at $65^{\circ} \mathrm{C}$ for 2 weeks to dry to determine dry weight (DW). Leaf RWC was calculated using equation: $(\mathrm{FW}-\mathrm{TW}) /(\mathrm{TW}-\mathrm{DW}) \times 100($ Barrs and Weatherly, 1962).

Turf quality (TQ) was visually rated based on color, density, and overall plant health on a scale of 1 to 9 with 1 being completely brown and dehydrated, 5 as moderately drought-affected turf, and 9 as healthy, green, dense canopy (Turgeon, 2008).

Canopy temperature depression [CTD (Rashid et al., 1999)] was calculated as the difference between the air and turf canopy temperature, which were monitored using a ambient temperature thermometer positioned in the growth chamber at canopy level and an infrared thermometer was used to measure canopy temperature (Model 2956; Spectrum Technologies).
Leaf electrolyte leakage (EL) was measured by taking $\approx 200 \mathrm{mg}$ of leaf samples from each plant. The tissue was briefly rinsed in deionized water and then put into $15-\mathrm{mL}$ tubes carrying $7 \mathrm{~mL}$ of deionized water. The samples were then placed on a shaker at room temperature overnight. The initial level of conductance $\left(C_{i}\right)$ was measured. Then the samples were boiled at $95{ }^{\circ} \mathrm{C}$ for $4 \mathrm{~h}$ to kill the leaf tissue and brought to room temperature with constant shaking for another $24 \mathrm{~h}$. The conductivity of the water containing the dead tissues was measured as the maximum conductance $\left(C_{\max }\right)$. The percentage EL was calculated as $C_{\mathrm{i}} / C_{\max } \times 100$ (Blum and Ebercon, 1981).

Membrane health attributes were estimated by measuring the following parameters. Leaf photochemical efficiency $\left(\mathrm{F}_{\mathrm{v}} / \mathrm{F}_{\mathrm{m}}\right)$ and quantum yield of photochemical energy conversion in PSII (YII) were determined with a fluorometer system (OSp5; OptiSciences, Hudson, NH) on individual, fully expanded leaves by taking three subsamples per plant. Leaf malondialdehyde content (MDA) to estimate lipid peroxidation level was determined with the method obtained from Dhindsa et al. (1981) with modifications. A $1.0 \mathrm{~mL}$ of enzyme solution was added to $2 \mathrm{~mL}$ of reaction solution containing $20 \%$ (v/v) trichloroacetic
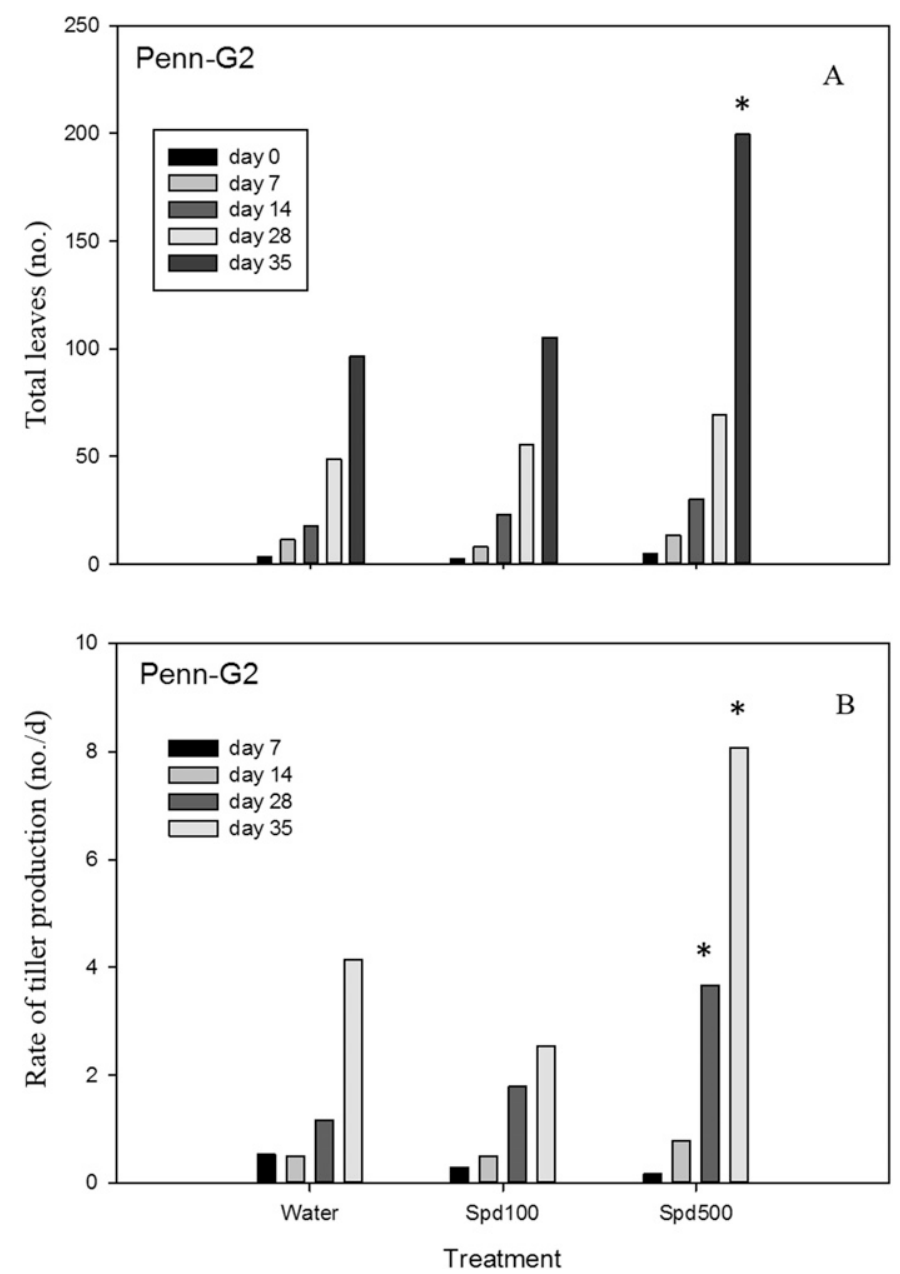

Fig. 1. (A) Total leaf number and (B) tillering rate of creeping bentgrass in a hydroponic growth chamber study in response to foliar treatment with water (control) or spermidine at 100 or $500 \mu \mathrm{M}$. Asterisks indicate statistically significant differences between chemical treatments on a given day of growth in the hydroponic system after chemical treatment. Asterisks were determined by Fisher's least significant difference tests $(\mathrm{n}=4)$ at $P \leq 0.05$. 
acid and $0.5 \%(\mathrm{v} / \mathrm{v})$ thiobarbituric acid. The solution was heated in a water bath at $95{ }^{\circ} \mathrm{C}$ for $30 \mathrm{~min}$, quickly cooled on ice, and centrifuged at $10,000 \mathrm{~g}_{\mathrm{n}}$ for $30 \mathrm{~min}$. A spectrophotometer (Genesys 20; Thermo Scientific, Waltham, MA) was used to measure absorbance of the solution at 532 and $600 \mathrm{~nm}$. MDA content was calculated by $600 \mathrm{~nm}$ subtracted from absorbance at $532 \mathrm{~nm}$ and then using this adjusted absorbance and extinction coefficient of $155 \mathrm{~mm}^{-1} \cdot \mathrm{cm}^{-1}$ (Heath and Packer, 1968).

EXPERIMENTAL DESIGN AND STATISTICAL ANALySis. All GC experiments were a completely randomized block design including four biological replicates for $\mathrm{GC} 1, \mathrm{GC} 2$, or six replicates for the hydroponic growth chamber study for each treatment. Effects of the chemical and drought treatment were analyzed over time by analysis of variance based on the general linear model procedure of SAS (Version 9.1; SAS Institute, Cary, NC). Fisher's protected least significant difference test at $P \leq 0.05$ was used to detect differences between treatment means.

\section{Results}

HYdRoponic GROWTH STUDY. The only growth regulator effects that occurred in response to PA application was a change in leaf number and tillering rate. A significantly greater number of total leaves was observed as a result of the presence of $500 \mu \mathrm{M} \mathrm{Spd}$ in the culture media at $35 \mathrm{~d}$ of growth (Fig. 1A). The rate of tillering was stimulated by Spd at $500 \mu \mathrm{M}$ treatment at 28 and $35 \mathrm{~d}$ of growth (Fig. 1B). Tillering rate was not significantly affected by all PA treatments (only Spd $500 \mu \mathrm{M}$ ) or on all dates. We found no significant differences in root biomass, root-to-shoot ratio, or leaf length (data not shown).

Water relations. SWC declined markedly in response to withholding water from drought-treated plants in both GC studies. SWC declined rapidly to $\approx 5 \%$ in each study (Fig. 2). There were no significant differences among chemical treatments in SWC either among well-watered plants or among drought-stressed plants in either of the GC studies (Fig. 2). Drought stress caused a significant decrease in CTD for both 'Penncross' and 'Penn-82'. Higher canopy temperatures were detected in drought-stressed plants compared with wellwatered plants; however, no significant differences were detected for CTD among chemical treatments (data not shown). RWC of plants decreased dramatically as a result of drought stress of both 'Penncross' and 'Penn-G2'. Significant differences among PA treatments within plants under drought stress occurred on 3, 5, and $7 \mathrm{~d}$ of drought stress during GC1 study of 'Penncross' (Fig. 2C) and on 5 and $8 \mathrm{~d}$ during GC2 study of
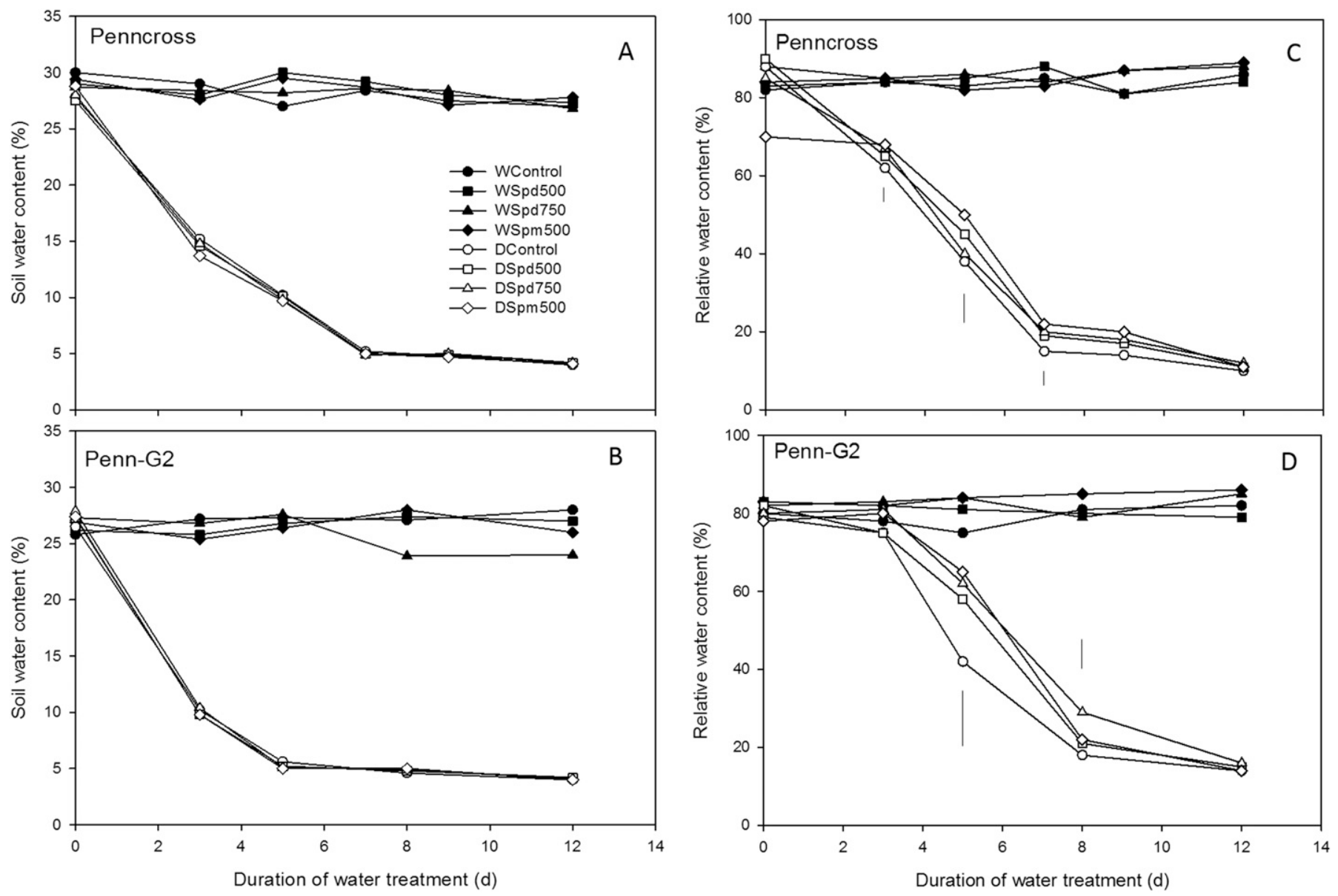

Fig. 2. Effect of water treatment and chemical treatment on the soil water content of creeping bentgrass (A) 'Penncross' and (B) 'Penn-G2'. Relative water content of leaves in response to water and chemical treatment for $(\mathbf{C})$ 'Penncross' and (D) 'Penn-G2'. Least significant difference (LSD) bars are present only on a given date where statistically significant differences were observed $(n=4)$ between chemical treatments $(P \leq 0.05) . \mathrm{W}=$ watered; $\mathrm{D}=\mathrm{drought}$; Control $=$ water plus Tween-20 (Sigma-Aldrich; St. Louis; MO); Spd = spermidine; $\mathrm{Spm}=$ spermine; $500=500 \mu \mathrm{M}$ treated; $750=750 \mu \mathrm{M}$ treated. 
'Penn-G2' (Fig. 2D). For instance, plants treated with Spm500 had a significantly higher RWC compared with the control plants on 5 and $7 \mathrm{~d}$ of drought stress of 'Penncross'. In 'PennG2', on 5 d drought stress. all PA-treated plants had a significantly greater RWC than control plants. By $8 \mathrm{~d}$ of drought stress, this difference was less apparent, because only droughtstressed Spd750 and Spm500 plants were significantly higher in RWC than control plants. Overall, 'Penn-G2' had a more marked response to PA treatment compared with 'Penncross' in terms of maintenance of RWC of leaves.

TURF QUALITY, MEMBRANe, AND PHOTOCHEMICAL HEALTH. Well-watered plants maintained relatively consistent levels of TQ, EL, $\mathrm{F}_{\mathrm{v}} / \mathrm{F}_{\mathrm{m}}$, and YII in both GC1 and GC2. No significant differences in any of these parameters occurred as a result of treatment with PA. For drought stress-treated plants, the TQ, $\mathrm{F}_{\mathrm{v}} / \mathrm{F}_{\mathrm{m}}$, and YII all declined markedly, whereas EL increased (Figs. 3 and 4). Drought-stressed plants treated with PA had significantly higher TQ in both GC1 and GC2 for the duration of the drought period (Fig. 3A and B). The TQ of 'Penncross' in GC1 was improved the most by treatment with Spm500 under drought stress. In GC2 with 'Penn-G2', treatment with Spd750 and Spm500 exhibited the greatest maintenance of TQ. Spd500 also improved TQ during drought stress of 'PennG2' but to a more moderate extent.
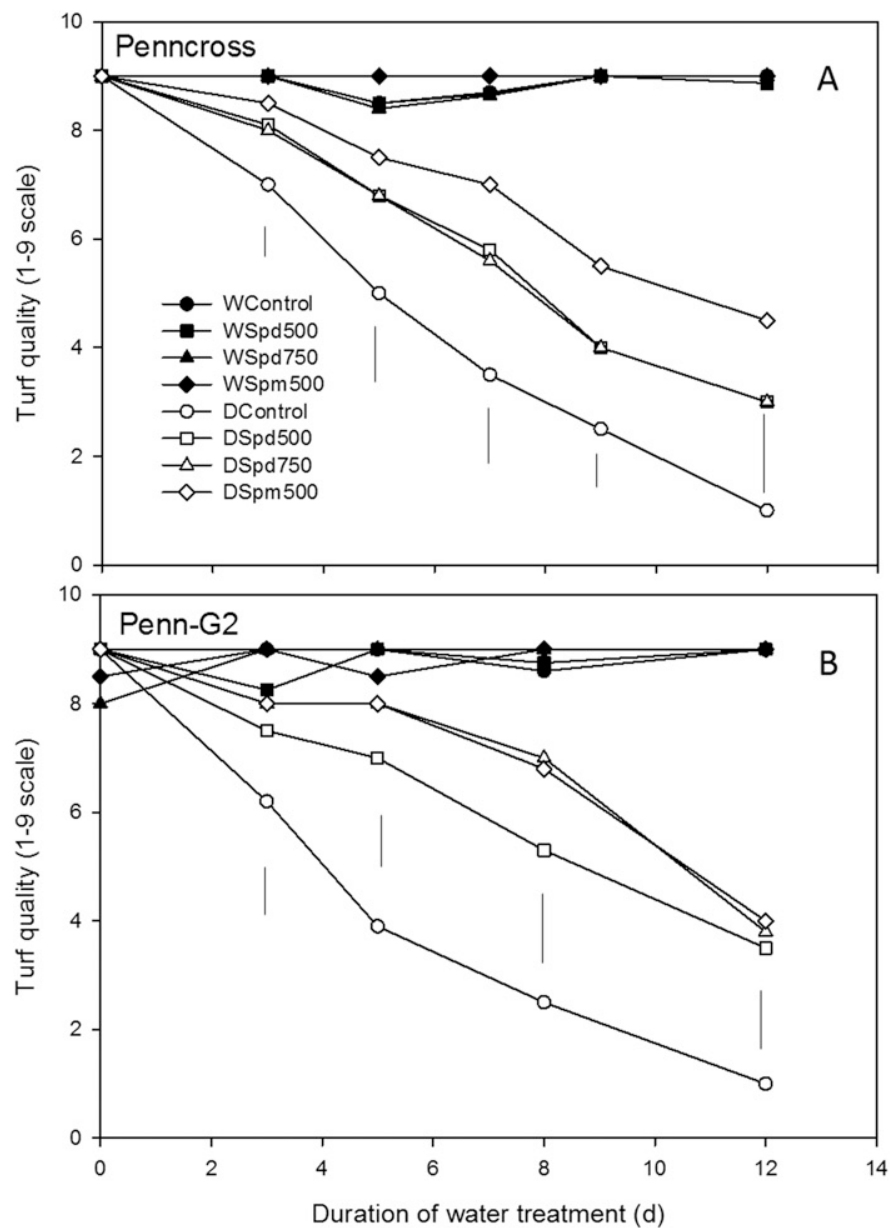

EL was increased to a greater extent in drought-stressed control plants compared with those plants treated with PAs in both GC studies (Fig. 3C and D). For GC1 with 'Penncross', EL was not significantly affected on all dates of drought stress, but there were significant reductions of EL as a result of treatment with Spm500 such as on 5 and $9 \mathrm{~d}$ of drought. A more dramatic separation of EL was observed in drought-stressed 'Penn-G2' plants in GC2. In this study, Spd500 was the most effective PA treatment because it consistently reduced EL of leaves on 5, 8, and $12 \mathrm{~d}$ of drought stress.

$\mathrm{F}_{\mathrm{v}} / \mathrm{F}_{\mathrm{m}}$ and YII were greatly reduced by drought stress in both cultivars of creeping bentgrass. Treatment with all tested PAs delayed the reduction in photochemical health $\left(\mathrm{F}_{\mathrm{v}} / \mathrm{F}_{\mathrm{m}}\right.$ and $\left.\mathrm{YII}\right)$. For instance, at $7 \mathrm{~d}$ of drought in 'Penncross' and $8 \mathrm{~d}$ of drought in 'Penn-G2', PA-treated plants had two to three times higher $\mathrm{F}_{\mathrm{v}} / \mathrm{F}_{\mathrm{m}}$ compared with control plants (Fig. $4 \mathrm{~A}$ and B). Similar results were observed for YII throughout the duration of drought treatment (Fig. 4C and D).

Lipid peroxidation (MDA content) was unchanged in wellwatered plants, whereas MDA increased significantly in drought-treated plants in both GC studies (Fig. 5). Overall, the MDA content increased more dramatically in control plants compared with PA-treated plants; however, this was not significant on all dates for all treatments. In GC1 for 'Penncross' (Fig. 5A),
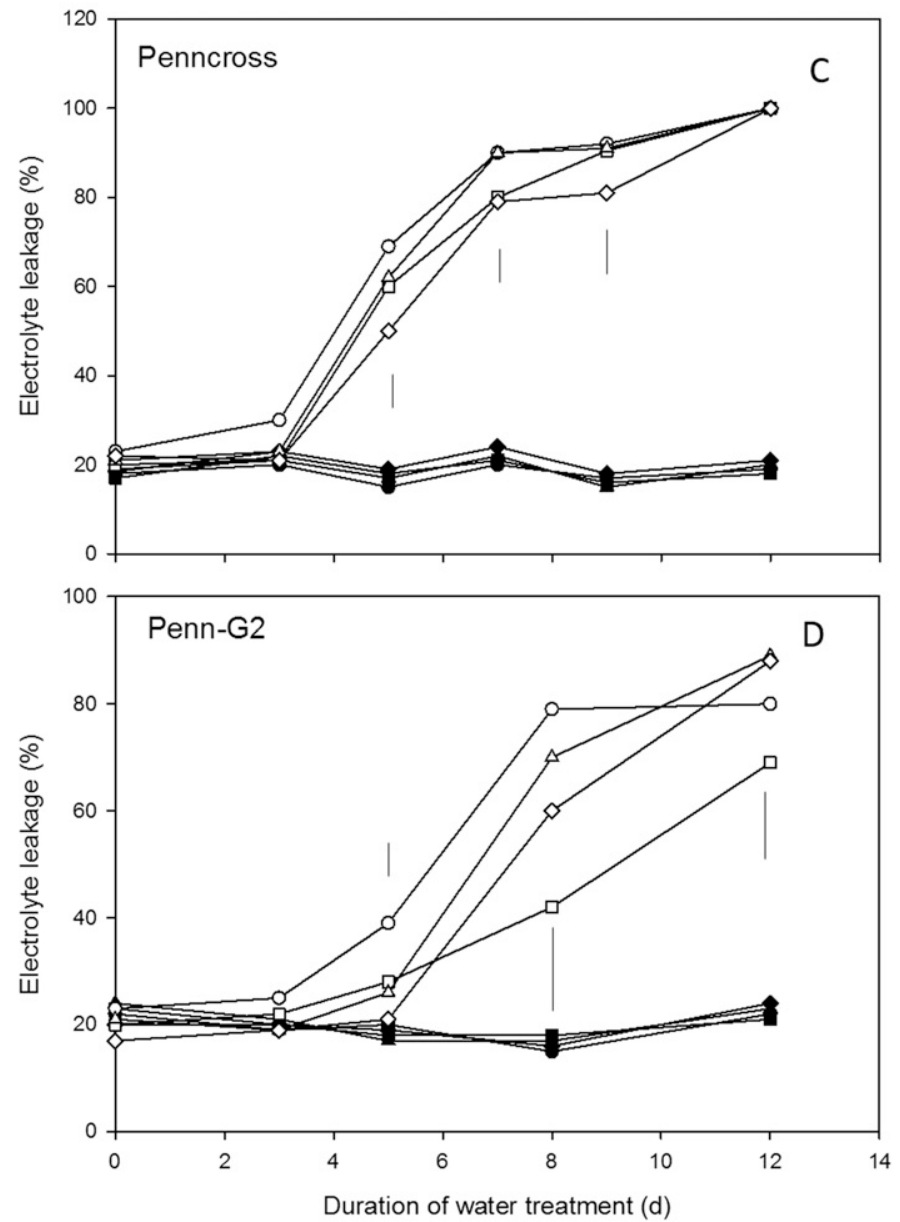

Fig. 3. Effect of water treatment and chemical treatment on the turf quality rating ( 1 to 9 scale; $1=$ worst $9=$ best $)$ of creeping bentgrass (A) 'Penncross' and (B) 'Penn-G2'. Electrolyte leakage of (C) 'Penncross' and (D) 'Penn-G2'. Least significant difference (LSD) bars are present only on a given date where statistically significant differences were observed $(\mathrm{n}=4)$ between chemical treatments $(P \leq 0.05)$. W $=$ watered; $\mathrm{D}=$ drought; Control $=$ water plus Tween-20 (Sigma-Aldrich, St. Louis, MO); Spd = spermidine; $\mathrm{Spm}=$ spermine; $500=500 \mu \mathrm{M}$ treated; $750=750 \mu \mathrm{M}$ treated. 

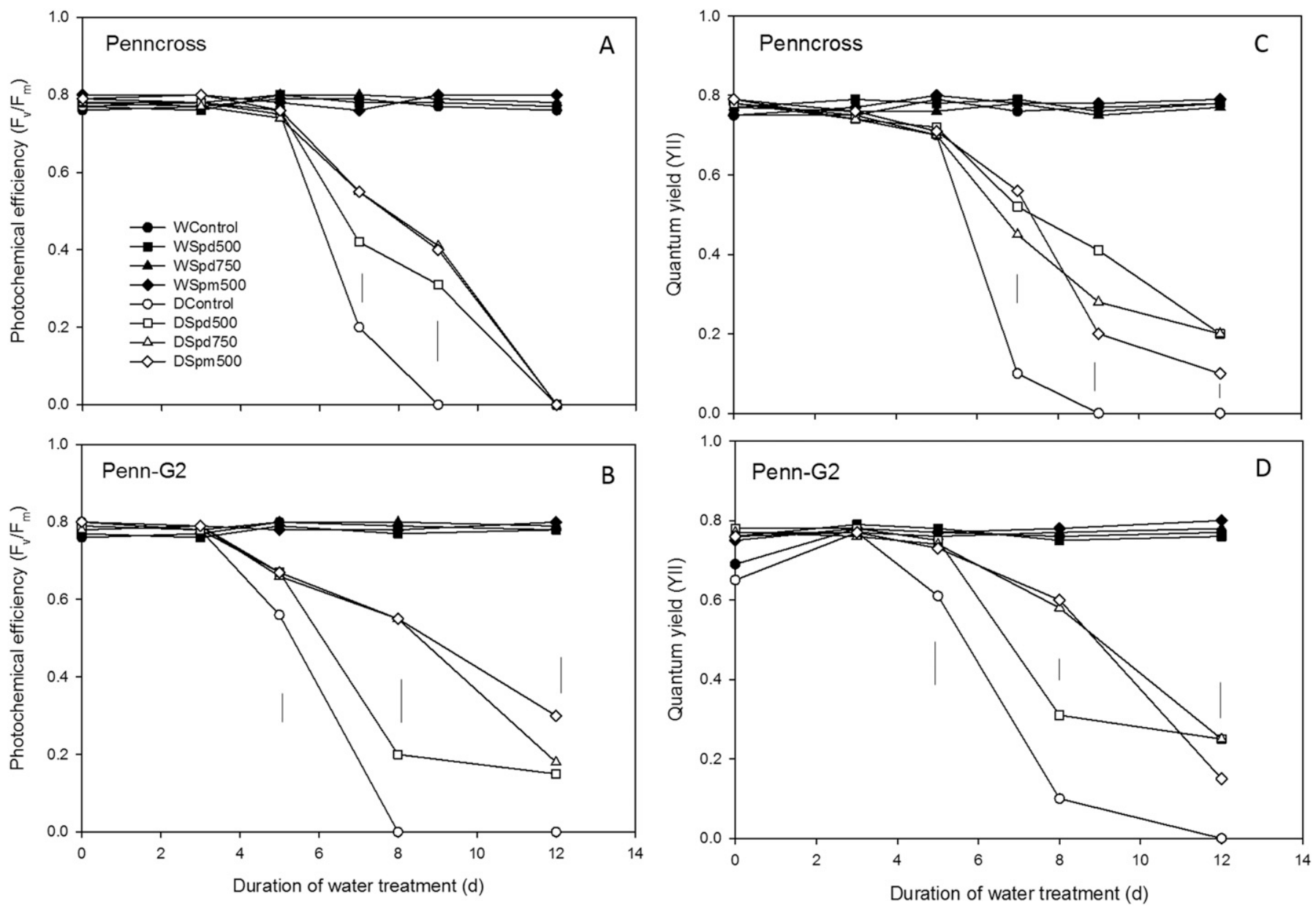

Fig. 4. Effect of water and chemical treatment on photochemical attributes of creeping bentgrass plants. The photochemical efficiency $\left(\mathrm{F}_{\mathrm{v}} / \mathrm{F}_{\mathrm{m}}\right)$ of $(\mathbf{A})$ 'Penncross' and (B) 'Penn-G2' creeping bentgrass and quantum yield of photochemical energy conversion in PSII (YII) of (C) 'Penncross' and (D) 'Penn-G2'. Least significant difference (LSD) bars are present only on a given date where statistically significant differences were observed $(n=4)$ between chemical treatments $(P \leq 0.05) . \mathrm{W}=$ watered; $\mathrm{D}=$ drought; Control $=$ water plus Tween-20 (Sigma-Aldrich, St. Louis, $\mathrm{MO}) ; \mathrm{Spd}=$ spermidine; Spm $=$ spermine; $500=500 \mu \mathrm{M}$ treated; $750=750 \mu \mathrm{M}$ treated.

Spd750 and Spm500 plants had less MDA accumulation compared with control drought-treated plants on 5 and $8 \mathrm{~d}$ of drought stress. Spd500 only showed significantly less MDA content after $8 \mathrm{~d}$ of drought. In GC2 for 'Penn-G2' (Fig. 5B), no significant difference in MDA content was detected until $8 \mathrm{~d}$ of drought treatment. On $8 \mathrm{~d}$, all PA-treated drought-stressed plants had significantly lower accumulation of MDA compared with control drought-stressed plants.

\section{Discussion}

To understand whether PA treatment has a growth regulatortype effect on creeping bentgrass plants, we have conducted a hydroponic study to determine whether changes occur in leaf biomass, root biomass, and tillering rate resulting from PA treatment under optimal conditions. Whether PA application played a major role in growth regulation is still not fully clear from the results of this study. We found that tillering rate was greater in Spd at the 500- $\mu \mathrm{M}$ level at 28 and $35 \mathrm{~d}$ of growth in the hydroponic system; however, no other growth parameters were significantly affected in leaves or roots as a result of PA treatment. Regardless of this, we have taken into account this potential change in tillering when interpreting the responses to drought stress. We have done this by eliminating the density component of TQ ratings that is typically done when rating turfgrasses (Turgeon, 2008). Thus, our TQ ratings are based primarily on green color, uniformity, and degree of wilting. Specific effects of PA treatment on tillering rate of grass or other plant species are not well documented. It is generally known that PA supplementation may stimulate plant growth and development through regulation of cell division and elongation (Kusano et al., 2008). Wheat (Triticum aestivum) plants exhibited a significant increase in growth characteristics in response to 50 to $100 \mathrm{mg} \cdot \mathrm{L}^{-1}$ of putrescine and Spd treatment (Ahmed et al., 2012). More detailed studies related to creeping bentgrass tillering and growth rate related to different concentrations of PA content may be desirable.

As a result of drought stress, creeping bentgrass plants exhibited significant stress symptoms and decline in health in both growth chamber studies that were conducted. As the SWC declined during the drought treatment, rapid cellular water loss occurred, which was apparent in the rapid reductions in RWC of creeping bentgrass leaves. Based on the parameters that were measured, one of the major consequences of drought was damage to cellular membrane structures, including the cellular membrane and photosynthetic membrane constituents. This is 

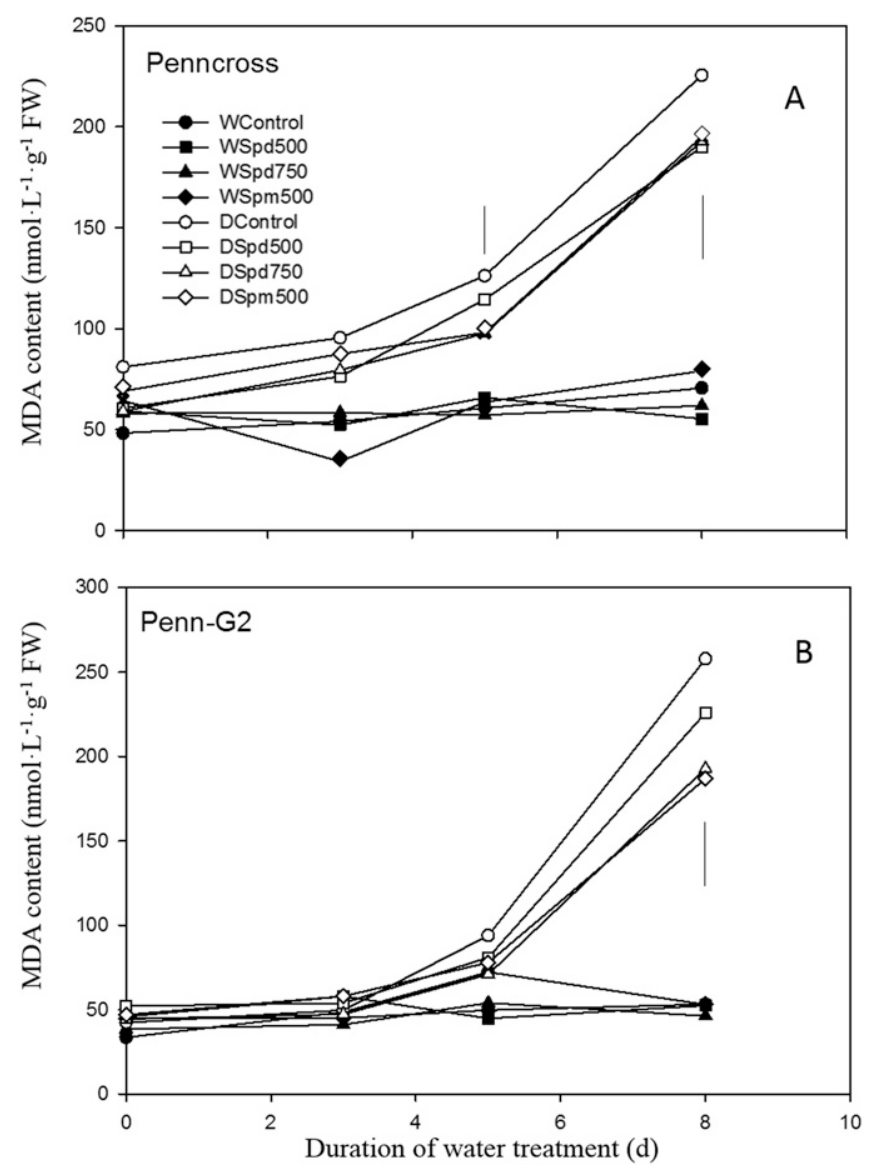

Fig. 5. Leaf malondialdehyde content (MDA) of creeping bentgrass (A) 'Penncross' or (B) 'Penn-G2' exposed to water or chemical treatments. Least significant difference (LSD) bars are present only on a given date where statistically significant differences were observed $(n=4)$ between chemical treatments $(P \leq 0.05)$. $\mathrm{W}=$ watered; $\mathrm{D}=$ drought; Control $=$ water plus Tween-20 (Sigma-Aldrich, St. Louis, MO); Spd = spermidine; Spm = spermine; $500=500 \mu \mathrm{M}$ treated; $750=750 \mu \mathrm{M}$ treated.

consistent with previous studies on drought stress of creeping bentgrass (Chai et al., 2010; Merewitz et al., 2011).

Based on the results of both GC studies, the PA treatments did not have a major effect on all water relations of creeping bentgrass under drought stress. The SWC declined at a similar rate for all plants in the studies and no significant differences were detected for CTD among chemical treatments. RWC of the leaves was found to be less in control plants compared with those treated with PA during the earlier stages of drought stress. This difference was more pronounced in 'Penn-G2' compared with in the study of 'Penncross'. Treatments with either Spm or Spd at the 500- $\mu \mathrm{M}$ level delayed leaf water loss during drought stress. These differences were not detectable by 10 (GC1) or 12 (GC2) d of drought treatment. The lack of effect of PAs on all water relations in this study could be related to the low rate of PA treatment used. Future work will include testing greater rates of PA to determine if there is a more marked effect on water relations during drought stress of turfgrasses.

The most readily observable response to PA treatments during drought stress was a significant improvement in the photochemical health of creeping bentgrass. In both growth chamber studies, we have observed a marked delay in the reduction of $\mathrm{F}_{\mathrm{v}} / \mathrm{F}_{\mathrm{m}}$ and YII caused by drought stress in PAtreated plants. This finding is consistent with previous literature that has noted that one major mode of PA action is on photochemical pathways within chloroplasts (Ioannidis and Kotzabasis, 2007). These researchers revealed that the concentration of applied Spd and Spm can affect the action of these compounds in chloroplast membrane photosystems. For instance, Spd and Spm enhance non-photochemical quenching at lower rates, whereas they uncouple photophosphorylation at higher concentrations. Duan et al. (2008) also found PAs to play a major role in preventing membrane damage in salt-stressed cucumber plants (Cucumis sativus). A promotion of $\mathrm{F}_{\mathrm{v}} / \mathrm{F}_{\mathrm{m}}$ health has been determined to be a major factor associated with drought tolerance of creeping bentgrass in many previous reports (Chai et al., 2010; McCann and Huang, 2008). We think that the marked increase in photochemical health and a moderate maintenance of RWC in some treatments could have been the major component that improved TQ ratings for PA drought-stressed plants compared with control droughtstressed plants. A delay in senescence could be related to maintenance of TQ but more work is needed to determine PA association with ethylene and leaf senescence in creeping bentgrass. In peach (Prunus persica) fruit, application of Spd was shown to delay the ripening process controlled by ethylene (Torrigiani et al., 2012). Consistent with the results of PA providing protection to the cellular membranes, we found that a lower amount of lipid peroxidation occurred in PA-treated plants under drought stress. Less MDA has also been associated with less leaf senescence (Dhindsa et al., 1981); however, whether MDA content was related to senescence cannot be directly concluded from the measurements done in this study. Similar results of PA application reducing MDA content were found associated with drought and salt stress of bermudagrass (Shi et al., 2013). Analysis of antioxidant enzyme activity and other membrane protective mechanisms in response to PA treatment may be of use to further discuss this finding in creeping bentgrass.

A low level of PA treatment mitigated some drought damage and moderately improved cellular water retention and photochemical health of creeping bentgrass. Because PAs seem to play a role in drought tolerance of creeping bentgrass, we are currently investigating how PA content changes as a result of stress and how phytohormones may relate to shifts in PA content. Additionally, studies of how PAs are altered by common management practices of turfgrass culture will be conducted in the future.

\section{Literature Cited}

Ahmed, M.A., M.A.F. Shalaby, and M.S.A. Abdallah. 2012. Growth and productivity of wheat as affected by putrescine and spermidine under water stress conditions. J. Appl. Sci. Res. 8:5068-5074.

Alcazar, R., M. Bitrian, D. Bartels, C. Koncz, T. Altabella, and A.F. Tiburcio. 2011. Polyamine metabolic canalization in response to drought stress in arabidopsis and the resurrection plant Craterostigma plantagineum. Plant Signal. Behav. 6:243-250.

Barrs, H.D. and P.E. Weatherly. 1962. A re-examination of the relative turgidity technique for estimating water deficits in leaves. Austral. J. Biol. Sci. 15:413-428.

Beard, J. 2006. Turfgrass management. 6th Ed. Prentice Hall, Upper Saddle River, NJ.

Bitrián, M., X. Zarza, T. Altabella, A.F. Tiburcio, and R. Alcázar. 2012. Polyamines under abiotic stress: Metabolic crossroads and hormonal crosstalks in plants. Metabolites 2:516-528.

Blum, A. and A. Ebercon. 1981. Cell membrane stability as a measure of drought and heat tolerance in wheat. Crop Sci. 21:43-47. 
Capell, T., L. Bassie, and P. Christou. 2004. Modulation of the polyamine biosynthetic pathway in transgenic rice confers tolerance to drought stress. Proc. Natl. Acad. Sci. USA 101:9909-9914.

Chai, X., F. Jin, E. Merewitz, and B. Huang. 2010. Growth and physiological traits associated with drought survival and post-drought recovery in perennial turfgrass species. J. Amer. Soc. Hort. Sci. 135:1-9.

Chaves, M.M., J.P. Maroco, and J.S. Pereira. 2003. Understanding plant responses to drought-From genes to the whole plant. Funct. Plant Biol. 30:239-264.

Cheng, L., Y. Zou, S. Ding, J. Zhang, X. Yu, J. Cao, and G. Lu. 2009. Polyamine accumulation in transgenic tomato enhances the tolerance to high temperature stress. J. Integr. Plant Biol. doi: 10.1111/j.17447909.2009.00816.x.

Dhindsa, R.S., P.P. Dhindsa, and T.A. Thorpe. 1981. Leaf senescence: Correlation with increased levels of membrane permeability and lipid peroxidation, and decreased levels of SOD and CAT. J. Expt. Bot. 32:93-101.

Duan, J., J. Li, S. Guo, and Y. Kang. 2008. Exogenous spermidine affects polyamine metabolism in salinity-stressed Cucumis sativus roots and enhances short-term salinity tolerance. J. Plant Physiol. 165:1620-1635.

Gill, S.S. and N. Tuteja. 2010. Polyamines and abiotic stress tolerance in plants. Plant Signal. Behav. 5:26-33.

Heath, R.L. and L. Packer. 1968. Photoperoxidation in isolated chloroplasts. Arch. Biochem. Biophys. 125:189-198.

Hoagland, D.R. and D.I. Arnon. 1950. The water-culture method for growing plants without soil. California Agr. Expt. Sta. Circ. 347.

Ioannidis, N.E. and K. Kotzabasis. 2007. Effects of polyamines on the functionality of photosynthetic membrane in vivo and in vitro. Biochimica Biophysica Acta Bioenergetics 1767:1372-1382.

Jiménez-Bremont, J.F., O.A. Ruiz, and M. Rodriguez-Kessler. 2007. Modulation of spermidine and spermine levels in maize seedlings subjected to long-term salt stress. Plant Physiol. Biochem. 45:812-821.

Kasukabe, Y., L. He, K. Nada, S. Misawa, I. Ihara, and S. Tachibana. 2004. Overexpression of spermidine synthase enhances tolerance to multiple environmental stresses and up-regulates the expression of various stress-regulated genes in transgenic Arabidopsis thaliana. Plant Cell Physiol. 45:712-722.
Kusano, T., T. Berberich, C. Tateda, and Y. Takahashi. 2008. Polyamines: Essential factors for growth and survival. Planta 228:367381.

McCann, S. and B. Huang. 2008. Evaluation of drought tolerance and avoidance traits for six creeping bentgrass cultivars. HortScience 43:519-524.

Merewitz, E., T. Gianfagna, and B. Huang. 2010. Effects of SAG12-ipt and HSP18.2-ipt expression on cytokinin production, root growth and leaf senescence in creeping bentgrass exposed to drought stress. J. Amer. Soc. Hort. Sci. 135:230-239.

Merewitz, E., T. Gianfagna, and B. Huang. 2011. Photosynthesis, water use, and root viability under water stress as affected by expression of SAG12-ipt controlling cytokinin synthesis in Agrostis stolonifera. J. Expt. Bot. 62:383-395.

Rashid, A., J.C. Stark, A. Tanveer, and T. Mustafa. 1999. Use of canopy temperature measurements as a screening tool for drought tolerance in spring wheat. J. Agron. Crop Sci. 182:231-237.

Shi, H. and Z. Chan. 2014. Improvement of plant abiotic stress tolerance through modulation of the polyamine pathway. J. Integr. Plant Biol. 56:114-121.

Shi, H., T. Ye, and C. Zhulong. 2013. Comparative proteomic and physiological analyses reveal the protective effect of exogenous polyamines in the bermudagrass (Cynodon dactylon) response to salt and drought stresses. J. Proteome Res. doi: 10.1021/pr400479k.

Torrigiani, P., D. Bressanin, K.B. Ruiz, A. Tadiello, L. Trainotti, C. Bonghi, V. Ziosi, and G. Costa. 2012. Spermidine application to young developing peach fruits leads to a slowing down of ripening by impairing ripening-related ethylene and auxin metabolism and signaling. Physiol. Plant. 146:86-98.

Turgeon, A.J. 2008. Turfgrass management. 8th Ed. Pearson Prentice Hall, Upper Saddle River, NJ.

Xie, S.S., H.J. Wu, H.Y. Zang, L.M. Wu, Q.Q. Zhu, and X.W. Gao. 2014. Plant growth promotion by spermidine-producing Bacillus subtilis OKB105. Mol. Plant Microbe Interact. 27:655-663.

Zhou, Q. and Y. Bingjun. 2009. Changes in free, conjugated and bound polyamine content in salt adaptation of vetiver grass (Vetiveria zizanioides, Poaceae). Acta Botanica Yunnanica 31:477-485. 